\title{
Long term short cuts
}

\author{
Professor Paul Wright \\ Chair, Central Committee for Dental Academic Staff \\ British Dental Association
}

Send your comments to the

Editor-in-Chief

British Dental Journal

64 Wimpole Street,

London

W1G 8YS

Email bdj@bda.org
The spectre of funding cuts is creating anxieties across higher education. In dentistry we already know of a small number of institutions that are looking to reduce the number of dental clinical academics they employ and we are concerned about the impact these reductions might have. Academic dentistry is already understaffed. A significant increase in student numbers in the second half of the 2000s was not accompanied by a corresponding increase in staff numbers. In fact, the number of academics decreased slightly between 2003 and 2008. Concern about this issue has increased to the extent that it appears as a priority in the British Dental Association's manifesto for the forthcoming General Election, among more fashionable and headline-grabbing topics such as Professor Steele's Review and patient access.

The funding cocktail for academic dentistry, where money comes from a number of sources, makes the potential scope and repercussions of funding cuts or freezes harder to assess than they might be in many other subject areas. A decision to reduce funding by the Higher Education Funding Council for England (HEFCE) may well be accompanied by a similar decision by the NHS, thereby producing a more severe impact on the funding of dental schools than other higher education disciplines.

And it is the solutions to, as well as the sources of, funding that are more complex in dentistry than elsewhere. Where in some subjects the feasible, if nonetheless unpalatable, solution to cuts might be to increase the number of students in lectures or tutorials, this is problematic in clinical dentistry, where many sessions are based on practical hands-on experience rather than observation. Every extra student being supervised in a clinical session without concomitant support means risking a reduction in the quality of care that can be assured.

\section{FULL RANGE OF DENTAL CONDITIONS NOT ENCOUNTERED}

A reduction in the amount of clinical tuition each student receives is no better a solution. Recent years have seen a reduction in the amount of clinical teaching time afforded to each dental student within the dental school environment. Although the amount of clinical time to which each individual is exposed may have been supplemented and enhanced in other primary care settings, the costs of such clinical experience do not constitute a saving, nor can they completely replace the secondary care experience necessary.

We should not delude ourselves that funding cuts will not hit teaching quality. International excellence in the Research
Assessment Exercise, which has for many years contributed to the wider health policy agenda, is something which I am proud to say the UK's dental schools achieve on a regular basis. This brings with it continued or increased funding. Funding for teaching is fixed. Institutions will, naturally, look to teaching rather than research-focused posts when considering which to reduce. It is increasingly common to appoint general dental practitioners to teach clinical sessions in dental schools providing a teaching-focused staff resource. However, this can be to the detriment of some specialties, which in turn means that dental students may not encounter the full range of dental conditions prior to embarking on their Foundation training.

Dental academia has faced recruitment problems for many years. The career path for academics is a long and difficult one and the financial rewards for success rarely match those in the NHS. This year's Doctors' and Dentists' Review Body report recognised this fact, reiterating the importance of there being sufficient incentives for dentists to choose academic careers. The report also supported the principle of pay parity between clinical academic staff and NHS clinicians, something that the BDA stressed in its own submission of evidence to the Body. This must include fair and equal access to additional Programmed Activities and the Clinical Excellence Awards Scheme.

The motivation for individuals opting for a career in dental academia is love of research, specialist clinical practice and teaching the aspiring dentists of tomorrow, but the high-calibre individuals the dental schools need must also earn a living and feel their abilities, expertise and hard work are acknowledged and rewarded.

The number of dental students has been increased at all of the UK's dental schools and three completely new centres have been created, at Peninsula, the University of Central Lancashire and Aberdeen. The increased number of graduates they will produce will help to address the problem many patients face accessing dental care, particularly in the cases of the new schools which have been deliberately situated with local difficulties in mind. Higher Education in dentistry is one of the few university disciplines that can truly be said to provide public and economic benefits to the nation. But to ensure that can happen, and that the dental graduates are able to deliver the full range of high-quality care their patients require, there must be caution in assessing the ability of dentistry to withstand funding cuts.

DOI: $10.1038 /$ sj.bdj.2010.255 